\title{
RESERVOIR SITE SELECTION AND MONITORING DURING CONSTRUCTION WITH APPLIED GEOPHYSICS
}

\author{
S. Penn \\ School of the Built Environment, Coventry University, United Kingdom
}

\begin{abstract}
The resent period of lower than average rainfall in the United Kingdom, together with changes in commercial factors and land use policy have been contributory aspects to an increased rate of the construction of water reservoirs for agricultural use in Eastern England. In this area there are large areas with chalk bedrock and glacially or fluvioglacially derived superficial deposits. The chalk is often modified or peri-glacially weathered and the superficial deposits vary between glacial till with a permeability of $10^{-8}$ $\mathrm{cm} \mathrm{s}^{-1}$ and fluvial sands with a permeability of $10^{2} \mathrm{~cm} \mathrm{~s}^{-1}$.

Reservoirs constructed with an artificial liner are expensive compared with a structure with a natural mineral liner'. Consequently sites with thick, laterally consistent, impermeable superficial deposits or outcropping clay strata are preferred.

Preliminary site selection is based upon a desk study of available geological information followed by a walk-over survey and trial pitting or boreholes. After laboratory testing to determine soil mechanics parameters, geophysics has frequently been used to investigate and map any lateral variations in thickness, and in some cases to investigate problematic ground conditions such as sand lenses with artesian water pressures.

Successful geophysical surveys and interpretations have proved the value of these techniques and there has been further application of the techniques to monitoring conditions during construction. For example mapping of the boulder clay reservoir floor thickness overlying an irregular chalk bedrock during excavation has been undertaken so that the amount of cut and placement can be carefully controlled. This ensures that there is the correct minimum thickness of impermeable clay floor over all the reservoir floor. There are obvious advantages to be obtained in the improved accuracy and spatial distribution of this information utilising geophysical techniques for this purpose. These advantages translates into efficiency gains with saving in both time and cost for the construction team.

A combination of electrical resistivity and conductivity techniques have been used, with carefull planning, interpretation and control to achieve a very high success rate in the correct prediction of ground conditions on these reservoir sites.

Details of the techniques used, data obtained, and the computer aided analysis and interpretation will be provided in the paper, with reference to a number of case studies from Eastern England.
\end{abstract}


The resistivities varied about $54 \mathrm{ohm}-\mathrm{m}$ (std. dv. 7.06). The north-east side, however, is an exception, with resistivities of $20 \mathrm{ohm}-\mathrm{m}$. The trend of increase from app. $200 \mathrm{~m}$ towards east is seen in all profiles (Fig. 2). In profile 3, the trend is abruptly broken by a significant decrease. The break is easily seen in profile 4 , although not as significant. In profile 5 , however, the increasing resistivities continues. This result shows a great accordance with the geology. The sand layer topography is reflected by the electrical results only in profile 5 , however the geology still looks the same in profile 3 and 4 . The decrease of resistivity, 40 ohm-m, may seem low, considering the common variation of resistivity, but the low standard deviation indicates a clear anomaly. The resistivity in this anomalous zone, when modelled with VES, is as low as $3-10 \mathrm{ohm}-\mathrm{m}$.

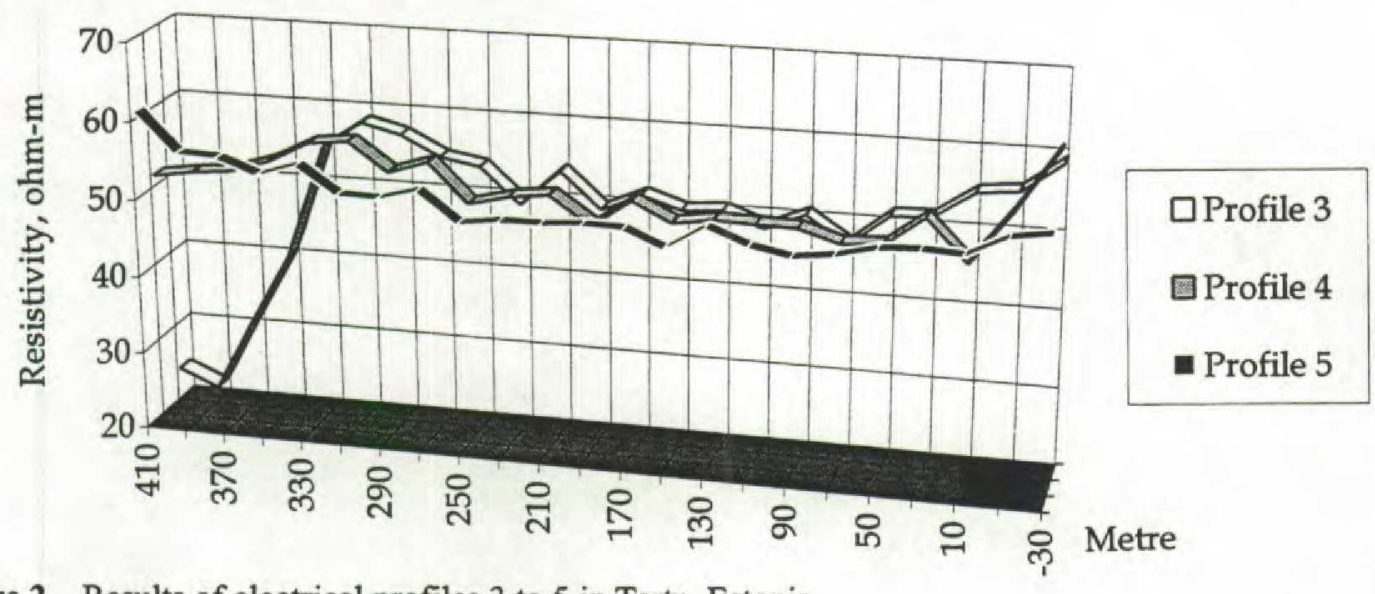

Figure 2. Results of electrical profiles 3 to 5 in Tartu, Estonia.

\section{COMMENTS I}

- Both the profiling and the sounding indicate an evident anomaly of low resistivity.

- Where the groundwater level and geological stratigraphy was well-known a suitable array could be chosen without preparatory soundings.

- A $20 \mathrm{~m}$ Wenner array in peat areas has a depth penetration corresponding to $\sim 0,15 \mathrm{~L}$ (Barker, 1989), which is in accordance with VES, steel-rod soundings and investigation tubes.

- The investigation should been completed with chemical analyses in a few shallow tubes.

\section{CASE II Hullaryd, Sweden}

Analyses of the groundwater in the village Hullaryd, north of the investigated landfill, have shown increasing salt content. No natural explanation was confirmed and antrophogenic sources have instead been discussed. De-icing salt and leachate from the landfill could be conceivable sources. Water analyses, both surface water and ground water, have shown increased salination right north of the landfill. The purpose was to provide clarity of the geological stratigraphy and map eventual leakage paths.

The area is characterised by a hilly terrain, with sand and gravel layers of about $10-20 \mathrm{~m}$ underlain by crystalline bedrock. Groundwater levels are found 6 to $13 \mathrm{~m}$ below the ground surface.

Refraction seismic fixed the bedrock level rather appropriate, but as the geology showed more complex than accounted a large number of hidden layers was suspected. VLF investigations indicated a possible fracture zone in a north-south orientation, somewhat east of the deposit, which could drain the topographically higher situated landfill. This zone is also indicated with both seismics and GPR as local depressions of the bedrock surface.

A low resistivity area, found with both electrical profiling and sounding, extends northwards somewhat west from the VLF indicated fracture zone and at a higher altitude (Fig. 3). As the topography is quite varying in the area, a first attempt has been made to deal with the fact that valleys in general show a lower resistivity naturally (shorter distance to the groundwater) compared to ridges in the terrain. In Aaltonen \& Blomqvist (1997) this low resistivity zone, shows low resistivity values, an indication of groundwater contamination. 


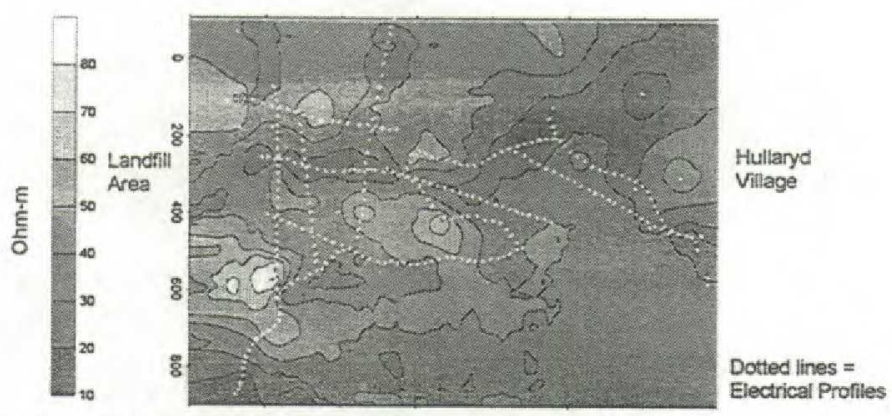

Figure 3. Contour map of the resistivity distribution at a depth of about $10 \mathrm{~m}$ in Hullaryd, Sweden.

COMMENTS II

- Two possible leakage path-ways were identified; in the bedrock and in the overburden.

- No indication of leachate was seen in the GPR measurements.

- A complex geology gave difficulties with the interpretation of both GPR and seismics.

- Seismic and GPR confirms the fracture zone which was detected by VLF. Seismic and GPR complement each other when determining the bedrock surface. The groundwater levels were seen both with resistivity and GPR measurements.

\section{CAse III Visby, Sweden}

The purpose of this investigation was to verify leachate from the municipal landfill at Visby, Sweden, and, if possible, confirm that the leachate was not moving eastwards. The landfill is located on limestone with a large extent of karst phenomena. The area is almost free of overburden and groundwater is found at different depths, between $1 \mathrm{~m}$ and $20 \mathrm{~m}$.

VES complemented with electrical profiles were done south and east of the landfill. The profiles were measured with a depth penetration of $10 \mathrm{~m}$ as the leachate was expected within $10 \mathrm{~m}$ below the ground surface. The results distinguished a low resistivity zone, compared to limestone resistivity in the area (800-1 $200 \mathrm{ohm}-\mathrm{m})$. This zone, with resistivities of 300-600 ohm-m, is found south-west of the landfill. In the area with lower resistivities, a complementary profile with a depth penetration of 5 meters was done, in order to study at which depth the lower resistivities could be found. The first $200 \mathrm{~m}$ was in accordance, which indicates a homogenous ground, whereas the last parts indicate superficial layers of poorer conductivity. VES also present layers of low resistivity. In the south-west the resistivity is 20 to $60 \mathrm{ohm}-\mathrm{m}$, lower than elsewhere. The depth to these layer varies, as could be expected in a karstic area. However, two zones, were identified, at 1 and $10 \mathrm{~m}$ depth (Fig. 4). VES in the eastern part does not show the same horizontal layering and have less variations, which may indicate a more coherent limestone.
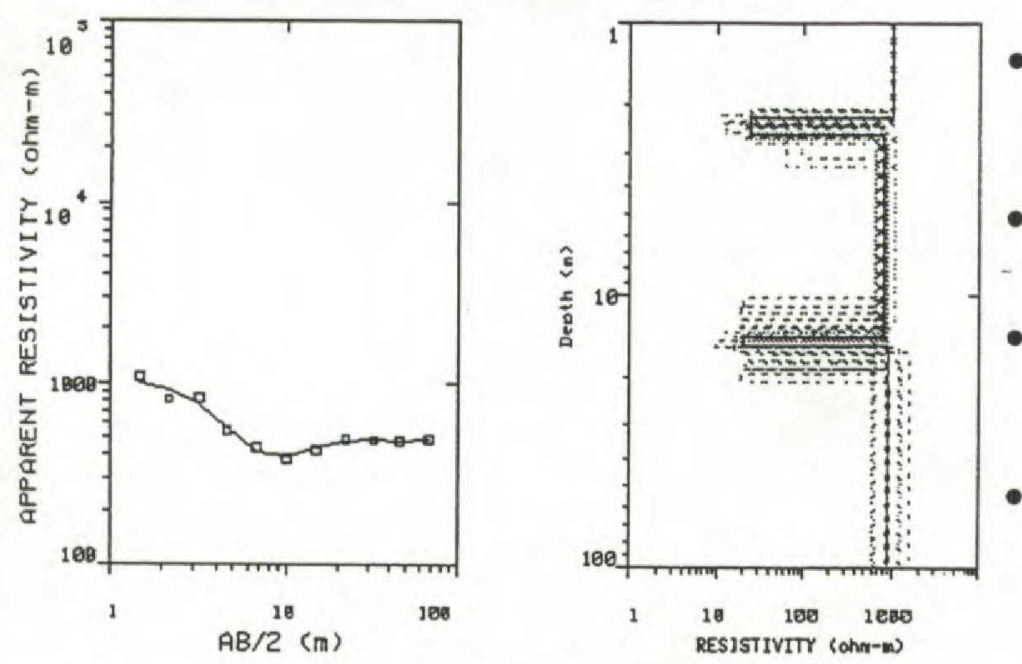

\section{COMMENTS III}

- Indications of leachate between blocks of limestone were found in the south-west part and no indication at all of any spreading eastwards.

- Modelling of VES is rather complicated with a multitude of layers, both thick and thin.

- If karstic structures are small they might be undetectable using electrical measurements, especially at large depths.

- More knowledge is needed of geological structures in the area, which may be obtained by e.g. GPR.

Figure 4. Example of one VES interpretation.

\section{Case IV Hult, Sweden}

The landfill at Hult has planned for an enlargement and also investigation of the system of protective ditches around the landfill. The purpose was the to see if any leachate could be 
detected right next to the landfill and also to make a pilot survey of the enlargement area. The geology consists of thick layers of peat, underlain by fine grained sands and clay, above a rather flat crystalline bedrock surface. The groundwater level is found $2 \mathrm{~m}$ below the ground surface. In the enlargement area the basement is more undulating, giving thinner or even absent peat layers.

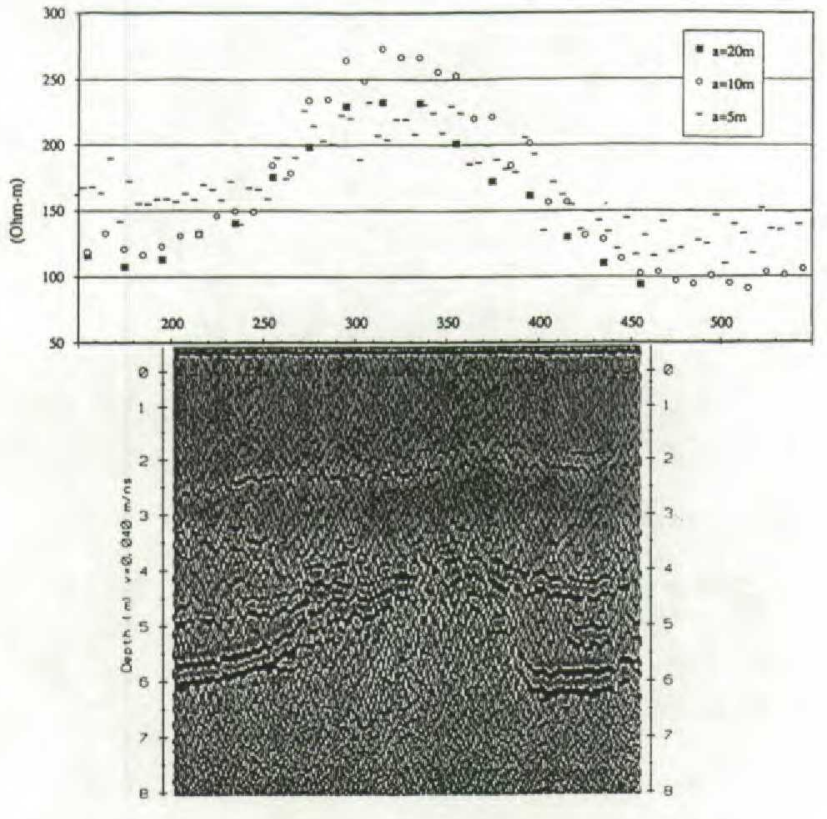

The resistivity profiles around the deposit did not indicate any leakage at all. Instead the measurements indicate different peat thicknesses and an undulating bedrock surface. This picture is completely confirmed by GPR (Fig. $5)$. VES indicate leakage between the two protective ditches, but no leachate outside the ditch system. More interesting is the comparison that was made with an older investigation, between which the sounding results correspond well.

The use of GPR in the enlargement area proved to be very successful. Where the overburden was rather thin, only $15 \mathrm{~m}$, a detailed picture of the geological structures was obtained, where layers of peat, gravel/sand, sand/fine sand and bedrock could be parted from each other.

Figure 5. Results of Wenner profiling and GPR.

\section{COMMENTS IV}

- No leachate could be detected outside the existing ditch system.

- VES proved to be repeatable, which is necessary if used for monitoring purposes.

- An overburden of peat and clay makes it difficult to separate possible leachate from low resistivity values due to natural geological conditions.

- GPR in peat environment is quite successful.

\section{SUMMARISING CONCLUSIONS}

- Leachates were most probably directly detected using electrical measurements at three of the four studied sites.

- Geological structures and possible flowpaths were detected by use of combinations of methods (VLF, GPR, electric and seismic measurements), which is most advisable.

- Electrical methods in combination with GPR are especially favourable for monitoring leachates and flowpaths in soil covered areas with complicated stratigraphy.

- A greater knowledge of the hydrogeological systems was clearly obtained by using geophysical methods.

\section{ACKNOWLEDGEMENT}

We would here like to thank our colleges G. Blomqvist, especially, and $\AA$. Fleetwood for assistance in field, thoughts and ideas and interpretation help in all these projects described.

\section{LIST OF REFERENCES}

Aaltonen, J. and Blomqvist, G., 1997. Resistivitet och topografi. In preparation. In Swedish.

Barker, R.D., 1989. Depth of investigation of collinear symmetrical four-electrode arrays. Geophysics, Vol. 54, No. 8, pp 1031-1037.

Benson, A.K., Payne, K.and Stubben, M.A., 1997. Mapping groundwater contamination using de resisitivity and VLF geophysical methods - A case study. Geophysics, Vol 72, No 1, pp 80-86.

Greenhouse, J.P. and Slane, D.D., 1986. Geophysical modelling and mapping of contaminated groundwater around three waste disposal sites in southern Ontario. Canadian Geotechnical J., Vol 23, pp 372-384.

Nobes, D.C., 1996. Troubled waters: Environmental applications of electrical and electromagnetic methods. Surveys in Geophysics, No 17, pp 363-454. 